\title{
MOVIMIENTOS SOCIALES E INTEGRACIÓN REGIONAL: EL CASO DE LA ARTICULACIÓN DE MOVIMIENTOS SOCIALES HACIA EL ALBA
}

\author{
Karla Díaz Martínez \\ karladiazm@yahoo.com \\ Universidad Arcis-Chile \\ Universidad Bolivariana de Venezuela
}

\section{RESUMEN}

El ALBA es un espacio de integración regional, alternativo al alca propuesto por EEUU, que inaugura una etapa denominada regionalismo posneoliberal. El ALBA desde sus orígenes ha contado con el acompañamiento de movimientos sociales de carácter antiimperialista y antineoliberal. La propia organización generó una instancia social: el Consejo de Movimientos Sociales; sin embargo, los movimientos sociales han generado de forma paralela y autónoma la Articulación de Movimientos Sociales hacia el ALBA. Este trabajo da cuenta de las características de este espacio de articulación social, a partir de propuestas teóricas pensadas en América Latina, y presenta un balance de las potencialidades y los desafíos de los movimientos sociales en el escenario latinoamericano y su influencia en la integración regional.

Palabras clave: integración regional, autonomía, democracia participativa, Mercosur. 


\title{
SOCIAL MOVEMENTS AND REGIONAL INTEGRATION: THE ARTICULATION OF SOCIAL MOVEMENTS TOWARD ALBA
}

\begin{abstract}
ALBA (the Bolivarian Alliance for the Peoples of Our Americas) is a regional integration entity created as an alternative to the US-proposed FTAA (Free Trade Area of the Americas, ALCA in Spanish). ALBA inaugurates a period that has been referred to as post-neoliberal regionalism. Since its origin, ALBA has been accompanied by social movements with an anti-imperialistic and anti-neoliberal stance. ALBA, itself, generated a social entity: the Social Movements Council. However, in a parallel and autonomous way, the social movements created the Articulation of Social Movements toward ALBA. This article describes the characteristics of this entity for social articulation based on theoretical proposals developed in Latin America, and presents a balance of the potentialities and challenges of social movements in Latin America and their incidence in regional integration.
\end{abstract}

Key words: regional integration, autonomy, participatory democracy, Mercosur. 


\section{INTRODUCCIÓN}

Los movimientos sociales y su relación con la integración regional en América Latina es la temática que aborda el presente trabajo, a partir del análisis de los antecedentes en el ámbito del Mercosur para luego centrar el estudio en la Alternativa Bolivariana para los Pueblos de Nuestra América (ALBA) y los espacios de encuentro de movimientos sociales que desde esa instancia se comienzan a articular en tiempos recientes.

La investigación se fundamenta teóricamente en la revisión de autores latinoamericanos que están pensando y describiendo los movimientos sociales propios de la región, con sus rasgos diferenciados de otros actores sociales colectivos. De ahí que consideremos como fuente autores que están pensando directamente en América Latina o que traducen los aportes norteamericanos y europeos a nuestra particular realidad.

Finalmente, a partir de los elementos teóricos y prácticos considerados se hace un balance de las potencialidades y los desafíos de los movimientos sociales frente a la integración regional de base en América Latina.

\section{ANTECEDENTES DE INTEGRACIÓN REGIONAL DESDE LOS MOVIMIENTOS SOCIALES:} LOS INTENTOS DESDE EL MERCOSUR

La trayectoria de los movimientos sociales ha estado determinada, naturalmente, por los momentos históricos y ciclos que vive su espacio territorial y social. En América Latina, de acuerdo con el periodo, han cobrado mayor relevancia los movimientos estudiantiles, los movimientos de pobladores, los frentes de lucha armada, las organizaciones eclesiásticas de base, los movimientos feministas y de mujeres, las organizaciones de familiares de detenidos desaparecidos, los movimientos indígenas, como muestra de la diversidad que ha acogido la organización a partir de los procesos sociales y momentos históricos. 
La década de los noventa fue particularmente compleja para la organización social porque se dieron procesos y transformaciones a nivel global que incidían de manera impactante sobre el tejido social. Fue una década que comenzó con la caída del Muro de Berlín y toda una serie de consecuencias políticas y culturales de carácter trascendente. Se dan por terminados los llamados socialismos reales, se define como potencia vencedora a los EEUU y con ello se instala toda una hegemonía cultural, económica y política que pasaría a conocerse como globalización.

En ese contexto, América Latina queda dentro del espacio de influencia directa de todos estos fenómenos. En el ámbito económico esto se concreta con una serie de políticas económicas dictadas por EEUU fundamentalmente para la región, conocidas como el Consenso de Washington y que no fue más que la implantación del modelo neoliberal en América Latina. Así, la década de los noventa estuvo caracterizada por estos ajustes económicos que se tradujeron para la sociedad en una serie de restricciones, privatizaciones, desregulaciones y flexibilización en el ámbito laboral; liberalización; el mercado fue mucho más libre de hacer y disponer; se restringieron significativamente las garantías sociales en salud, educación y servicios.

El impacto en la sociedad fue dramático y aparecieron las consecuencias sociales. Los sectores más afectados, que resultaron ser muy amplios, comenzaron a manifestar su descontento frente a estas acciones. En algunos casos las protestas fueron de tal magnitud que marcaron un antes y un después en la historia de los países. En el caso de Venezuela el Caracazo de 1989; en Ecuador el levantamiento indígena que a su vez representaba la demanda de otros sectores de esa sociedad; posteriormente, en Argentina, la crisis financiera y política de 2001.

La globalización, esa que comenzaba y se instalaba en la década de los noventa, que traía aparejada la internacionalización de los Estados y que prometía, a través del Consenso de 
Washington superar el estancamiento económico, los problemas de desarrollo y apuntalar el crecimiento, no fue tal cosa. En ese marco surge el Mercosur en 1991, como proyecto de integración económica y estrategia para enfrentar los nuevos tiempos, para integrar esos nuevos espacios de internacionalización de los mercados.

El Mercosur es visto como un instrumento para enfrentar la globalización (Carrera 2005), como una unión aduanera (Katz 2006), o como espacio de integración económica por otros. Sin embargo, y más allá de estos adjetivos que lo han venido caracterizando, el Mercosur ha sido uno de los principales espacios de encuentro de Sudamérica, de ahí que en el momento de su constitución y en el contexto social complejo en el que emerge genera reacciones desde los espacios de organización social en general y desde los movimientos sociales en particular. Se generaron altas expectativas al respecto, en cuanto a la relación entre Mercosur y lo social; identificamos al menos tres momentos: en un primer momento, si bien era claro que formaba parte de la lógica neoliberal, se pensó que se abriría un espacio de integración que también podría ser social; sobre todo desde la organización sindical, se esperaba que se podría avanzar en la articulación de centrales sindicales latinoamericanas y en políticas laborales comunes que beneficiaran a los trabajadores de todo el espacio Mercosur. Un segundo momento se vislumbra prontamente cuando se evidencia que el Mercosur no prevé tal espacio de articulación social y tampoco se corresponden esas reivindicaciones con sus intereses primarios, más bien abocados al mercado sin considerar a los trabajadores, mucho menos aquellos movimientos sociales distintos a los laborales, aunque con la llegada de gobiernos progresistas se intentó dar algunos pasos en el ámbito social. Un tercer momento recién comienza, ya que con la efectiva entrada de Venezuela en el Mercosur y el ingreso de Bolivia (ya en proceso de Adhesión $^{1}$ ) se abren nuevos escenarios, y especialmente Venezuela ha planteado la intención de influenciar al bloque sudamericano con algunas de sus políticas sociales más relevantes (misiones sociales de alfabetización, de salud visual, Mercosur Indígena, Mercosur Obrero) y al mismo tiempo trasladar al Mercosur los espacios de intercambio 
social latinoamericanos que se vienen abriendo en el ALBA, integrados por movimientos y organizaciones sociales.

El Mercosur, como asociación subregional, desempeña una función muy trascendente en la región, sobre todo por el hecho de que incluye a las dos naciones con mayor peso en el cono sur: Brasil y Argentina. Si bien fue concebido como una unión aduanera, a diferencia del alca que como proyecto pretendía constituir una zona de libre comercio, y la Unión Europea que se ha forjado como un mercado común (Ghiotto en Katz 2006), su presencia, su trayectoria y su peso ha sido determinante para marcar el rumbo de la integración en la región. De ahí que por su importancia esté llamado a intentar establecer vínculos con los sectores sociales de la región, y a fortalecer algún tipo de integración desde las bases sociales.

De acuerdo con lo plateado hasta aquí, identificamos tres etapas en la relación entre lo social y el Mercosur. A continuación apuntamos algunos detalles que describen las dos etapas iniciales.

En un primer momento, desde la organización sindical se esperaba avanzar en la articulación del ámbito laboral, a pesar de que era clara la tendencia neoliberal del bloque, acorde con los tiempos que se vivían. A finales de los años ochenta, el Cono Sur concluyó su larga transición del periodo desarrollista al modelo de internacionalización de los mercados internos, lo que significó una reducción del papel del Estado, la apertura de los mercados financieros y comerciales, la profundización de los cambios tecnológicos en los procesos de trabajo y la flexibilización de los sistemas de relaciones laborales. Y frente a esos cambios el sindicalismo tuvo que sostener una política de resistencia (Portela de Castro 2007: 67).

En 1986 se crea la Coordinadora de Centrales Sindicales del Cono Sur (CCSCS), que 
reivindicaba desde el principio la profundización de la integración como mecanismo para superar la crisis de la época. Esta organización se mantuvo en resistencia frente a la complejidad de la situación de flexibilidad laboral y precarización del empleo. Después, con el giro a la izquierda en los gobiernos del Sur, la CCSCS adoptó una postura bastante optimista respecto de la posibilidad de cambiar el rumbo del Mercosur, buscando que se convirtiera en instrumento para la construcción de un nuevo modelo de desarrollo económico y social Sin embargo, desde 2004 aducían que después de diez años de constituido el bloque se seguía aplicando un modelo exportador y de subordinación de la política a la estabilidad financiera y monetaria, y que por tanto era necesaria «la adopción de una nueva agenda macroeconómica que contemplara temas fundamentales como integración productiva e inversiones» (Portela de Castro 2007: 70-71).

La organización laboral es el movimiento que ha tenido mayor visibilidad y ha ocupado mayores espacios dentro del Mercosur; sin embargo, no han logrado mayores avances, del lado de las organizaciones sindicales nacionales no han dado prioridad al Mercosur en sus agendas, y del lado de la institucionalidad no ha habido una estrategia regional de inspección del trabajo, ni presupuesto adecuado, ni investigación suficiente (Portela de Castro 2007: 79).

De acuerdo con Garcés (2007:4), no basta con solidarizarse con las luchas de otros movimientos como se ha hecho hasta ahora; es necesario «dar un salto cualitativo que implique algo así como «compartirnos» en términos de saberes y de horizontes políticos, con el objeto de articular plataformas de luchas compartidas. Pero, incluso más, con el objeto de ir configurando una nueva cultura política latinoamericana». Ambas afirmaciones apuntan a que el poco avance en la integración social es en buena parte responsabilidad de los movimientos sociales y las estrategias que se han adoptado en los últimos tiempos; sin embargo, también encontramos que la falta de voluntad política y las limitaciones de la institucionalidad del Mercosur ha sido determinante en los resultados negativos de la 
integración social.

En una segunda etapa, cuando ya se había entendido que no era posible que el Mercosur sirviera como vehículo para profundizar la integración social, se dieron algunos pasos, de iniciativa institucional que intentaban incluir la participación social.

Pero a la vez, en esta etapa llegan al poder algunos gobiernos progresistas que intentan cambiarle la cara al bloque. El Programa Somos Mercosur, iniciativa de Uruguay durante la presidencia de Tabaré Vásquez en 2005, intenta rescatar lo social, lo político y lo cultural del Mercosur. Ha sido calificado como poco efectivo, si no se lleva adelante una reingeniería institucional y metodológica en favor de la transparencia, la inclusión de nuevos actores y la democratización del bloque (Vázquez 2008: 148).

El Programa Mercosur Social y Solidario (PMSS), la manifestación más importante, viene desarrollando estrategias en el nivel local, nacional y regional desde 2003, reivindicando derechos políticos, económicos y sociales. Se trata de una plataforma de la sociedad civil. De acuerdo con los datos del propio programa está integrada por 17 ONG de los países miembros del Mercosur, articula unas 150 organizaciones y movimientos sociales, incluyendo a más de 3,000 representantes de organizaciones sociales de jóvenes, mujeres, campesinos y pobladores (Programa Mercosur Social Solidario 2010).

Desde antes existía el Foro Consultivo Económico y Social, ${ }^{2}$ creado en 1994, que agrupa a organizaciones empresariales, sindicatos y tercer sector, sin participación de los Estados. No se concibe como espacio exclusivo para los movimientos sociales, sino más bien como espacio de encuentro de sectores diversos de la sociedad civil.

Con la llegada de gobiernos progresistas a los países del bloque se impulsa un cambio de perspectiva y la apertura de espacios institucionales al debate con las organizaciones 
sociales, pero no parece ser suficiente para transformar un bloque de integración que ha sido concebido desde sus orígenes como un espacio de intercambio comercial que ha imposibilitado la interacción con los sectores sociales (como los movimientos sociales) que no encentran en Mercosur un proyecto propio de integración social.

En este contexto nacen las «contra cumbres» o «cumbres de los pueblos», donde los movimientos sociales plantean sus propuestas y otro tipo de integración. «Este giro en la denominación de las cumbres no fue casual, obedeció a los cambios de regímenes políticos producidos en algunos países del Mercosur» (Programa Mercosur Social Solidario 2010). La Cumbre de los Pueblos de Mar del Plata (2005) que buscaba enfrentar al alca, y efectivamente logró su derrota, marcó el nacimiento del ALBA, y a la vez influenció y afianzó la organización social a nivel regional.

La tercera etapa, de acuerdo con lo que antes apuntamos, comienza con la entrada de Venezuela en el bloque, que se concreta en julio de 2012, y en julio de 2013 dicho país asume temporalmente la Presidencia, con importantes propuestas en el ámbito social, encaminadas a ampliar al espacio regional algunas de las más efectivas políticas sociales que Venezuela ha implantado dentro de sus fronteras con resultados exitosos, fundamentalmente las misiones sociales. ${ }^{3}$

\section{REGIONALISMO POSNEOLIBERAL E INTEGRACIÓN: EL CASO DEL ALBA}

La Alternativa Bolivariana para los Pueblos de Nuestra América (ALBA) como espacio de integración regional surge en 2004, y marca el inicio de una nueva etapa en la integración latinoamericana, lo que algunos denominan regionalismo posneoliberal (Serbin 2010: 1). Nace en el contexto de un rediseño de la región, en un nuevo marco geopolítico (Katz 2006) caracterizado por el «desplazamiento de los temas de liberalización comercial y desregulación por una agenda marcadamente política signada por el retorno a un rol 
protagónico del Estado [...] con la redefinición de un espacio sudamericano caracterizado por la exclusión explícita de EEUU» (Serbin 2010: 1).

En el año 2001 Venezuela y Cuba sellaron el nacimiento de ALBA; ${ }^{4}$ sin embargo, se suele hacer énfasis en su «epicentro venezolano» a partir de que desde ese país se impulsa la iniciativa en tres niveles: como resultado del proceso bolivariano, como esbozo de intercambio comercial cooperativo y como proyecto estratégico de unificación latinoamericana (Katz 2006: 65).

La Cumbre de los Pueblos de Mar del Plata en 2005 marca un hito en este sentido. En el marco de la Cumbre de las Américas de la OEA se organiza una marcha en repudio a la presencia del presidente de EEUU George Bush, a la vez que se realiza una contracumbre en la que se canceló el alca (Área de Libre Comercio de las Américas) como propuesta norteamericana.

De acuerdo con Luis Brito García, el ALBA nace de la resistencia al alca, pero también de una nueva lógica que entiende el carácter economicista y mercantil de uniones encaminadas a la ampliación del comercio mutuo. Ambos factores generaron la necesidad de un proyecto más amplio para la integración de América Latina y el Caribe (Brito 2009: 171), que sería el ALBA.

Esta alianza se reviste de un carácter antiimperialista, por ser una propuesta alternativa al alca, de un carácter anticapitalista, que persigue un tipo de relación distinta de la comercial y que no sea exclusiva con EEUU, y hace hincapié en las relaciones de tipo humanista y solidaria a partir de los Tratados de Comercio de los Pueblos (TCP), y contempla el integracionismo como objetivo principal.

Es particularmente importante destacar que el ALBA ha sido el espacio desde el que se ha 
impulsado y puesto en funcionamiento el Sistema Único de Compensación Regional (SUCRE 2013) como mecanismo de intercambio en la región, sustitutivo del dólar como moneda internacional, y que ya está siendo empleado en transacciones entre los países miembros (al 29 de octubre de 2011 se habían realizado unas 250 operaciones mediante dicho sistema, que equivalen a \$198.7 millones de dólares (Sistema Unitario de Compensación Regional de Pagos 2013).

La alianza, integrada por Venezuela, Cuba, Bolivia, Ecuador, Nicaragua, Dominica, San Vicente y las Granadinas, y Antigua y Barbuda, va avanzando en su constitución definitiva. En 2009 definen los principios fundamentales de los Tratados de Comercio de los Pueblos (TCP) contrapuestos a los TLC ${ }^{5}$ y fundamenta su comercio en base a principios como la complementariedad, la solidaridad y la cooperación. El TCP cuestiona los aspectos librecambistas que rigen no sólo en los tratados bilaterales, sino también en muchos compromisos del Mercosur (Katz 2006: 99). Siempre en la lógica de construir alternativas concretas al proyecto estadounidense

La estructura del ALBA prevé la existencia de diversas instituciones: Consejo Político, Consejo Económico, Consejo Social, y Consejo de Movimientos Sociales. Este último es definido por la propia organización como «el principal mecanismo que facilita la integración y participación social directa en la Alianza (ALBA-TCP) y tiene como misión articular a los Movimientos Sociales de los países miembros del ALBA-TCP y a aquellos de países no miembros que se identifiquen con este esfuerzo, y tiene la responsabilidad de aportar al desarrollo y ampliación del proceso del ALBA-TCP» (ALBA-TCP 2013).

En el marco de la V Cumbre de la organización que tuvo lugar en Tintorero, Venezuela, en abril de 2007, se realizó un encuentro en el que se propuso, por una parte, la adhesión de los movimientos sociales a la organización, pero respetando el principio de autonomía y estructura horizontal de éstos, en una integración que permitiera el diseño de planes, 
programas y proyectos. Por otra parte, se planteó la articulación de aquellos proyectos nacionales cuyo objetivo fuera la unidad y el reconocimiento de la diversidad de los movimientos sociales y políticos para convertir el ALBA en una herramienta inclusiva de las amplias mayorías de nuestros pueblos (ALBA-TCP 2013).

Posteriormente, en 2008 se propuso la definición y funciones del futuro Consejo de Movimientos Sociales (CMS), y un año más tarde se realiza la primera Cumbre de Movimientos Sociales, Pueblos y Naciones de los países miembros de la ALBA. Todo esto, después de haber aprovechado algunos otros espacios de encuentro como la Escuela Nacional Florestan Fernández, propiciado por el MST y la Vía Campesina Brasil, el Foro Social Américas de Guatemala en 2008, y el VIII Foro Social Mundial de Belem do Pará en Brasil, donde se fue gestando esta agrupación de movimientos en torno al ALBA.

De acuerdo con el propio manifiesto,

esta Primera Cumbre del Consejo de Movimientos Sociales en el marco del ALBA-TCP, es una Cumbre histórica que permite la participación directa de los movimientos sociales en los diferentes medios de cooperación y solidaridad, a diferencia de otros mecanismos de integración de países, que nunca han considerado la participación plena de los pueblos y naciones, limitándose a meros intercambios de intereses mercantilistas que van en contra de la integración y reciprocidad de pueblos y naciones de la gran Abya Yala (Latinoamérica) (CMS-ALBA 2009).

Pero a la par de este CMS emerge otra propuesta de integración de base. Se trata de la Articulación de Movimientos Sociales hacia el ALBA (AMSALBA).

Durante la V Cumbre del ALBA (Tintorero, Venezuela 2007) se sugiere la construcción del ALBA, no sólo desde la institucionalidad de los gobiernos sino también a partir de un Consejo de Movimientos Sociales (CMS) de los países signatarios de este organismo. 
De igual manera los movimientos y organizaciones sociales decidieron dar un salto propositivo y construir un espacio más amplio de integración de los sectores populares del hemisferio, donde tengan un papel cada vez más protagónico en los cambios que acontecen en nuestra región (ALBA Movimientos 2012).

Se hace especial énfasis en la distinción entre ambos espacios, y en el boletín de la organización se declara: «esta estructura [CSM-ALBA], que incluye a organizaciones y movimientos de los países signatarios del ALBA y cuenta con nuestro apoyo por su importancia para la lucha en la región, es independiente de la Articulación de Movimientos Sociales hacia el ALBA que venimos construyendo» (Boletín de la articulación Continental de movimientos sociales hacia el ALBA 2012).

La AMSALBA «de forma más autónoma, [funciona] a partir de una secretaría operativa provisional, en diálogo con las plataformas nacionales que están conformando organizaciones y movimientos en nuestros distintos países» (ALBA Movimientos 2012).

El imperativo ético político que se han trazado es el de construir plataformas nacionales y un instrumento de coordinación; «potenciamos la articulación de abajo y a la izquierda, que precisa de un claro proyecto organizativo, que debe reunir de forma plural a todos los movimientos y fuerzas populares que adhieran al proyecto de integración ALBA de los Pueblos en cada país» (ALBA-Movimientos 2012).

De igual manera, la AMSALBA destaca el carácter estratégico del tema comunicacional en su campo de acción. Cuentan con un boletín informativo, una página web, un canal de televisión, y a la vez articulan toda una red comunicaciones conformada por cada uno de los medios de los movimientos sociales que forman parte de la articulación en toda la región.

A este respecto, destacan conceptos como el de «independencia», el de accionar de «forma 
autónoma», y la «articulación de abajo», con los que remarcan su carácter de movimientos sociales auténticos, y concurren a la caracterización de los movimientos latinoamericanos como autónomos, pero en compleja relación con lo institucional, en este caso en el ámbito regional. Al mismo tiempo están generando alternativas a los espacios institucionales impulsados desde arriba.

\section{LOS MOVIMIENTOS SOCIALES EN AMÉRICA LATINA Y SUS CARACTERÍSTICAS}

Actores sociales colectivos es la categoría que abarca tanto a los movimientos sociales como a los partidos políticos y los grupos de presión. Aun cuando entre los movimientos sociales y los otros hay múltiples elementos que los distinguen, como la débil estructura orgánica, una orientación hacia el poder que suele ser conflictiva, y la naturaleza de los recursos que emplean, que suelen ser más que materiales de carácter simbólico (Martí 2010).

Garretón (2004) distingue entre los movimientos sociales (minúscula y plural) que son formas de acción colectiva que responden a tensiones específicas o contradicciones e intentan resolverlas. Mientras que Movimiento Social (mayúscula inicial y en singular) es portador de un sentido de la historia y la encarnación de una fuerza para un amplio cambio social. Por lo tanto, es posible que dos o más movimientos sociales constituyan un Movimiento Social.

El objeto de análisis de este trabajo son los movimientos sociales y su relación con los espacios de integración en América Latina, aun cuando la distinción entre actores sociales colectivos y movimientos sociales en nuestra región no llega a ser dicotómica. En múltiples contextos se da una interacción permanente o temporal entre la organización social y la organización política. Algunos movimientos han constituido partidos políticos que los representen en el ámbito electoral, y más recientemente, algunos de nuestros países tienen 
en el poder nacional a presidentes llevados hasta esa posición por la fuerza y el impulso de movimientos y colectivos de movimientos (Evo Morales en Bolivia es el caso más representativo de esto).

A efecto de entender la relación entre movimientos sociales e integración regional, particularmente la relación entre ALBA y AMSALBA, consideramos pertinente hacer una caracterización de los movimientos latinoamericanos a partir de elementos particulares y distintivos. Esto se hará sobre la base de tres aportes teóricos construidos especialmente desde y para América Latina:

\section{MESTIZAJE}

De acuerdo con Raúl Zibechi (2003), el mestizaje es una característica propia de los movimientos sociales latinoamericanos. Se da a partir de la confluencia de diversas corrientes político-sociales, que históricamente han influido en su armazón ético y cultural: las comunidades eclesiásticas de base vinculadas a la teología de la liberación; la insurgencia indígena y el guevarismo inspirador de la militancia revolucionaria. Mestizaje que claramente se plasma en la AMSALBA, donde se agrupan movimientos con diversas demandas, formas de organización y orígenes, y que sería una de las características distintivas de los movimientos latinoamericanos, y de esta agrupación de movimientos en particular.

La AMSALBA, objeto de este análisis, como colectivo de movimientos diversos denota esta característica. Integrada por movimientos con diversidad de demandas, como es el caso de la Alianza Sexo-Género Diversa Revolucionaria (ASGDRE) de Venezuela; Movimiento Sin Tierra (MST) de Brasil; Asociación Campesina del Valle del Río Cimitarra (ACVC) de Colombia; Frente Popular Darío Santillán (FPDS), Central de Trabajadores de la Argentina (CTA-Capital), Federación Universitaria de Buenos Aires (FUBA) de Argentina; Organización de solidaridad de los Pueblos de África, Asia y América Latina (OSPAAAL) 
capítulo Cuba, ${ }^{6}$ que denotan la pluralidad de actores.

En esta diversidad de demandas, que es una característica descrita como «impureza» por Boaventura de Sousa, radica la verdadera novedad de los nuevos movimientos sociales en América Latina. «Por ejemplo, es probable que un movimiento de orientación clasista esté acompañado de juicios étnicos y sexuales, que lo diferencian y lo asimilan a otros movimientos de orientación culturalista con contenidos clasistas» (De Sousa 2001: 181). Entonces, el mestizaje como característica y cualidad de los movimientos sociales latinoamericanos se encuentra presente en AMSALBA, y por tanto puede llegar a influir con esa diversidad el espacio del ALBA.

\section{REAFIRMACIÓN DE LA IDENTIDAD Y CULTURA}

Entre las tendencias principales de los nuevos movimientos sociales en América Latina está su trabajo por la «revalorización de la cultura y la reafirmación de la identidad de sus pueblos y sectores sociales» (Zibechi 2003: 186). Los movimientos indígenas y los movimientos de mujeres, feministas y de sexo-género diversidad han jugado un papel clave en dicha revalorización cultural en cuanto a la afirmación de las diferencias étnicas y de género, y dentro de la AMSALBA tienen una fuerte presencia y una destacada visibilidad.

Se conformidad con lo anterior, es desde la identidad desde donde los actores sociales generan un proceso de construcción de sentido, y así las identidades organizan ese sentido, mientras que los roles organizan las funciones (Castells 1997: 29). Se identifican diferentes tipos. Manuel Castells ha elaborado una clasificación que distingue entre identidad legitimadora, identidad de resistencia e identidad proyecto.

La identidad legitimadora es aquella introducida por las instituciones dominantes para extender y racionalizar su dominación frente a los actores sociales (Castells 1997: 30). El 
Consejo de Movimientos Sociales del ALBA podría estar inserto en esta clasificación de las identidades, a partir de que constituye un espacio instalado desde la institucionalidad del ALBA para reunir a los movimientos sociales como aliados, y para integrar sus demandas y propuestas a los espacios de decisión de la institucionalidad.

Por su parte, la identidad de resistencia es aquella generada por los actores que se encuentran en posiciones/condiciones devaluadas o estigmatizadas por la lógica de la dominación, por lo que construyen trincheras de resistencia y supervivencia. Mientras que la identidad proyecto se da cuando los actores construyen una nueva identidad que redefine su posición en la sociedad, y buscan la transformación de toda la estructura social, siendo el movimiento feminista el ejemplo por excelencia de este tipo de construcción identitaria (Castells 1997: 100).

La AMSALBA está más cercana a la identidad de resistencia en vista de que han construido un espacio propio de interacción, distinto del propuesto por la institucionalidad, y a la vez podría ser considerada dentro de la identidad proyecto, ya que aunque si bien no se trata de un solo movimiento, como para analizarlo en ese nivel, pretende constituirse como un espacio de interacción e integración desde las bases, desde los propios movimientos sociales y populares, para articular la integración regional en el ámbito social, con la diversidad de movimientos que lo constituyen, lo que da lugar a un proyecto transformador.

\section{AUTONOMÍA}

Entre los estudios de los movimientos latinoamericanos hay una coincidencia en relacionar la autonomía con los movimientos indígenas, por el cuestionamiento que estos hacen a las bases constitutivas del Estado nación, siendo el movimiento zapatista la máxima expresión de esta autonomía (Ceceña 2001, Seoane et al. 2006, Svampa 2010). Sin embargo, la relación entre los movimientos por un lado, y el Estado y los partidos políticos por el otro, 
es una relación tensionada que suele presentar constantes oscilaciones en torno a la cooptación, la subordinación, la cooperación y la ruptura frontal.

Una de las principales tensiones en la acción colectiva, según Fernando Calderón (1995:100), está «entre la tendencia hacia la autonomía con respecto al Estado y los partidos políticos de una parte, y por la otra, la búsqueda de dependencia, articulación y formas de heterenomía y cooptación». Pero los resultados de esa lucha pueden dar por resultado varias tendencias, entre las cuales la más positiva parece ser que «pueden recrear nuevos sistemas de acción y reconectarse con el sistema de poder [...] [que] implicaría la transformación en los sistemas de representación y legitimidad-legalidad política».

Esta tensión está en constante movimiento, y varía no sólo respecto de un gobierno y otro, sino que puede haber relaciones variables entre los mismos actores. Analizando el Movimiento Sin Tierra (mst) de Brasil, Martha Harnecker hace un acercamiento a esta realidad cuando describe la relación de este movimiento con el gobierno de Fernando Henrique Cardoso (1994-1998), y distingue cuatro momentos: primero, la estrategia del gobierno fue «ignorar» el movimiento; en un segundo momento aplicó la «cooptación» de dirigentes; en el tercero «aisló» y decidió no negociar; y finalmente, en un cuarto momento aplicó el «garrote», es decir ,la represión, que fue lo que terminó predominando (Harnecker 2002: 59).

En el caso de Bolivia, que es uno de los países integrantes del ALBA y con fuerte presencia de movimientos sociales e indígenas, se discute constantemente el tema de la autonomía. Se ha teorizado sobre la idea de «gobierno de los movimientos sociales como contradicción». El Estado es por definición concentración de decisiones, monopolio sobre la coerción, la administración de lo público-estatal, e ideas-fuerza que articulan a una sociedad. En cambio, el movimiento social y las organizaciones sociales son por definición democratización de decisiones, amplia y continua socialización de deliberaciones y 
decisiones sobre asuntos comunes. Gobierno de movimientos sociales es por tanto una tensión creativa, dialéctica, productiva y necesaria entre concentración y descentralización de decisiones (García Linera 2011: 28).

En todo caso, son muchas las críticas que desde los propios movimientos se hace a este «gobierno de movimientos», como apunta Raquel Gutiérrez: en la actitud de los movimientos bolivianos en esta coyuntura se nota un nuevo margen de autonomía política recuperada ante las decisiones gubernamentales, toda vez que han comprendido que el gobierno será incapaz de detener a la oligarquía, pero no están, al menos tendencialmente, dispuestos a subordinarse a que ese gobierno les garantice lo que anhelan (Zibechi 2009: 3).

La premisa que prevaleció a comienzos de la primera década del 2000, cuando los gobiernos progresistas se posicionaban en el poder, con fuerte apoyo de movimientos sociales y populares, fue «la idea de deslindar campos entre las fuerzas sociales y las políticas. Aunque las primeras tienden a apoyar a las segundas, conscientes de que gobiernos progresistas pueden favorecer la acción social, no parece fácil que vuelvan a establecer relaciones de subordinación» (Zibechi 2003: 188). En este sentido, el contexto actual parece estar abriendo las posibilidades al incremento de la autonomía, de la cual se apropian los movimientos y, en consecuencia, y más allá de las tensiones, se fortalecería un espacio crítico frente a las gestiones gubernamentales que puede enriquecer y fortalecer los procesos de transformación del Estado que se pretenden en algunas sociedades de la región.

\section{LA AUTONOMÍA FRENTE A LOS GOBIERNOS PROGRESISTAS}

Se distinguen dos momentos en la relación entre movimientos sociales y gobiernos progresistas, siguiendo a Zibechi (2009). En una primera etapa no parece posible superar la dependencia y la subordinación de los movimientos hacia los Estados, sin comprender que los nuevos gobiernos de izquierda y progresistas pusieron en pie nuevas formas de 
dominación, entre las cuales los planes sociales destinados a integrar a los pobres juegan un papel destacado en el diseño de nuevos modos de control social a cielo abierto (Zibechi 2009: 4).

En este sentido, una perspectiva de análisis crítica a este planteamiento induce a concluir que si bien existe menor movilización, puede ser consecuencia de que hay menores carencias, necesidades básicas mucho mejor cubiertas que en periodos anteriores en que la precariedad condujo a desórdenes sociales sin precedentes en toda la región latinoamericana (Caracazo, Movimiento Forajido, Guerra del Agua y del Gas, por mencionar algunas).

En un segundo momento, de acuerdo con Zibechi (2009), el Estado asume los discursos y hasta las propias prácticas de los movimientos, y al respecto aparecen tres cuestiones: $a$ ) el fin de la vieja derecha: se da un desplazamiento de las redes clientelares para colocar en su lugar a las burocracias estatales, y al hacerlo apelan al mismo lenguaje y códigos de los movimientos; $b$ ) las nuevas formas de control, que se manifiestan en planes sociales, muchas veces ejecutados por las ong, que trabajan con los sectores que se habían organizado en movimientos, para desorganizarlos; y c) la ofensiva contra la autonomía, haciendo que los movimientos participen en las políticas locales (Zibechi 2009).

En todo caso, esto no se debe a la maldad de los nuevos gobiernos, «cada vez que los de abajo desbordan las formas de dominación, aparecen necesariamente otras nuevas, más perfeccionadas que las anteriores. Sólo neutralizando estos planes sociales, superando esta ofensiva contra la autonomía de abajo, los movimientos pueden volver a ponerse de pie y reemprender los caminos de la emancipación» (Zibechi 2009: 6).

En el momento actual existe una compleja relación. El panorama de algunas sociedades latinoamericanas se caracteriza por el desplome de los modelos neoliberales como 
consecuencia de la acción de los movimientos sociales y el derrocamiento de gobiernos, ${ }^{7}$ y por la posterior llegada al poder de gobiernos progresistas (Argentina, Uruguay, Brasil) y

revolucionarios (Venezuela, Ecuador, Bolivia ${ }^{8}$ ) con el apoyo de esos mismos movimientos sociales. Lo anterior denota que tales movimientos no sólo han sido un actor en la escena política y social, sino protagonistas y agentes de cambios en algunos de los procesos recientes, tanto en sociedades que buscan romper con el paradigma neoliberal (en diferentes niveles), como en otras que aún no comienzan ese rompimiento.

El caso más emblemático es el movimiento estudiantil chileno, que en 2011 irrumpió, llevó a la ciudadanía a las calles y destapó primeramente una crisis de credibilidad respecto del gobierno, pero más profundamente, y desde una perspectiva del tiempo largo de los movimientos, destapó un problema de fondo y más complejo: una crisis de legitimidad del sistema político (Garcés 2012: 16). Es el ejemplo de una sociedad que aún no rompe con el modelo neoliberal pero que muestra agitación y descontento social.

\section{POTENCIALIDADES Y DESAFÍOS DE LA INTEGRACIÓN REGIONAL DE BASE}

La AMSALBA, objeto de este análisis, se vislumbra como espacio propicio para avanzar en la integración regional desde las bases, cuenta con una serie de potencialidades orientadas hacia la integración social como objetivo, o a la práctica de la Diplomacia de los Pueblos (Ticona 2006, Barreto et al. 2007, Díaz 2011) propuesta por los procesos de transformación del Estado en Ecuador, Venezuela, y sobre todo en Bolivia, rescatando las prácticas de la diplomacia indígena pero apuntando al establecimiento de relaciones de sectores diversos sin la presencia protagónica del Estado. Pero evidentemente, así como cuenta con potencialidades se enfrenta a una serie de desafíos.

La primera potencialidad de la AMSALBA se encuentra en las características que la distinguen, y que son propias de los movimientos sociales latinoamericanos: el mestizaje 
político que permite la diversidad y la pluralidad de proyecto y de acción; el factor de rescate identitario y de revalorización de la cultura que contribuye al proceso de integración regional a partir de lo cultural y desde el reconocimiento de elementos comunes; el rescate de las culturas indígenas originarias; y procesos recientes de enfrentamiento al proyecto neoliberal que articulan una suerte de identidad común pero diversa que reivindica un proceso de integración regional desde lo social como necesario e indispensable para un nuevo tipo de desarrollo.

El segundo elemento positivo se encuentra en que la presencia activa de los movimientos sociales dentro de espacios institucionales de integración o de acompañamiento de estos espacios y la presentación de propuestas frente a temas trascendentes repercute en la profundización de la democracia participativa en el ámbito regional. Por una parte, las prácticas políticas internas de los movimientos sociales, que suelen ser más horizontales y participativas, pueden comenzar a permear otros ámbitos; y por otra parte, una apertura de espacios para la creación colectiva en lo político, es decir, el socialismo como la construcción de una cultura donde sea posible la creatividad como experiencia cotidiana (Moulian 2001: 163).

La tercera potencialidad es el aporte a la agenda política nacional y regional que hacen los movimientos sociales, y esto no es un elemento reciente, ni es restrictivo de las sociedades con gobiernos progresistas o que se han dado a la tarea de la transformación del Estado. Por el contrario, ha sido una característica histórica, y visible con mucha más fuerza en sociedades como la chilena, donde la emergencia de demandas de movimientos sociales va influyendo en la agenda política, por ejemplo, en el tema de la educación, pero sobre todo en los conflictos medioambientales (caso Hidroaysen, caso Freirina), capaces de paralizar y cancelar grandes proyectos económicos.

El cuarto elemento potencial orientado hacia la integración regional es que la apertura de 
espacios sin restricciones, manifiesto en el hecho de que tanto la AMSALBA como el CMSALBA integran no sólo movimientos de los países parte del alba, a partir de que es una articulación de acompañamiento a este proyecto de integración, sino movimientos sociales de toda la región, e incluso del sur global. Es el caso del MST de Brasil que no forma parte del alba, y de la Organización de Solidaridad de los Pueblos de África, Asia y América Latina (OSPAAAL).

De igual manera los desafíos son múltiples y complejos. En primer lugar, se enfrentan a las llamadas nuevas formas de control (Zibechi 2009) que se manifiestan en planes sociales. Sin embargo, esta dinámica tiene un doble carácter, porque si bien aparecen frente a un desborde social, por un lado apaciguan la conflictividad y el desborde; pero por otro lado los movimientos sociales muchas veces ven satisfechas sus demandas y carencias con estos planes sociales, sobre todo en áreas prioritarias como los servicios básicos (agua, vialidad), salud, educación o alimentación.

Un segundo desafío sería poder conducir la tensión entre la postura de las instituciones regionales, que buscan establecer un vínculo con su base social que se traduzca en respaldo y también como una manera de hacer más efectivas las políticas sociales a partir de la participación de los movimientos en la gestión y su apoyo. Frente a la postura de la organización social, que busca fortalecerse como actor regional, reivindicar sus luchas en un ámbito mayor, y muchas veces llevar sus prácticas al espacio institucional.

En tercer lugar se deberá superar la sectorización que ha caracterizado los movimientos sociales de la región. «Muchos de los foros sociales, regionales y mundiales, son de otra naturaleza. La mayoría son sectoriales, por ejemplo, las organizaciones indígenas, las organizaciones campesinas, las confederaciones sindicales, los intelectuales, las feministas, los economistas, etcétera» (Dieterich 2007). De ahí la importancia de un espacio como la AMSALBA que supera lo sectorial, y además se caracteriza por la pluralidad de actores en su 
seno.

La carencia de una estructura regional organizada por los movimientos sociales sería otro de los desafíos. Comúnmente se realizan encuentros y foros pero que carecen de una organización estructural. En este sentido la AMSALBA si bien aún está en proceso de conformación, propone una estructura organizativa regional, a partir de que desde ya cuentan con una Secretaría Operativa Provisional en el nivel regional, y múltiples plataformas a nivel nacional.

El quinto desafío consistiría en incrementar la incidencia política concreta, más allá de la capacidad de enfrentarse a proyectos, de derrocar presidentes o de hacer frente a la implantación de un modelo neoliberal. La poca incidencia es una de las características de los movimientos sociales de la región. Muchas veces «algunos rechazan querer ser políticos [...] lo que es obviamente ridículo; como si fuera posible ser apolítico en una sociedad de clases» (Dieterich 2007). En ocasiones hay cierta incidencia política, pero con poca propuesta de alternativas, es el caso de los movimientos sociales con mayor grado de enfrentamiento con el Estado y sus gobiernos.

Más recientemente ha surgido un desafío más complejo. El ingreso de Venezuela y Bolivia en el Mercosur pone en entredicho la importancia del ALBA como proyecto de integración alternativo, y tiende a otorgar más peso en la región al Mercosur, que está creciendo en cuanto a número de países miembros, cuenta ahora con el elemento energético (el petróleo de Venezuela y el gas de Bolivia) como recurso estratégico dentro del bloque. Si el desbalance regional llega a inclinarse en contra del ALBA podrían perder fuerza los proyectos de organización social que lo acompañan, pero al mismo tiempo siendo el AMSALBA una articulación autónoma, tiene la posibilidad y el reto de participar de los espacios sociales que el Mercosur, con Venezuela dentro, pretende abrir a la participación social. 


\section{CONCLUSIONES}

Los movimientos sociales en el contexto regional latinoamericano están llamados a dos grandes tareas. La primera es avanzar en la construcción colectiva de una integración regional de base que fortalezca y apoye una integración regional institucional. La segunda es avanzar en el fortalecimiento de la democracia participativa, trasladarla al plano internacional en la región, a partir de hacer trascender sus prácticas, sus formas de organización y de lucha.

En estas importantes tareas, la Articulación de Movimientos Sociales hacia el ALBA puede llegar a jugar un papel protagónico como actor en el escenario regional, activo en la proposición y el debate de los temas trascendentes, en múltiples ámbitos, superando lo sectorial, y en la construcción de una alternativa política. Está llamada a convertirse en un articulador de muchas organizaciones cuya fortaleza permita lograr un amplio cambio social en el ámbito regional, hacia la necesaria integración y unión latinoamericana y caribeña.

\section{FUENTES DE CONSULTA}

ALBA-TCP, 2013, «Consejo de Movimientos Sociales del ALBA-TCP» en http://www.albatcp.org/contenido/consejo-de-movimientos-sociales-0 [consulta: 10 de noviembre de 2012].

ALBA Movimientos, 2012, «¿Quiénes somos?» en http://www.albamovimientos.org/ \%C2\%BFque-es/ [consulta: 10 de noviembre de 2012].

Barreto, Heiber, Patricia Méndez, Mabel Bravo y Christian Flores, 2007, «Diplomacia de los pueblos» en Fundamentos filosóficos de la nueva integración del Sur, compilado por Héctor Constant, Instituto de Altos Estudios Diplomáticos Pedro Gual, Caracas, pp. 44-53. 
Boletín de la Articulación Continental de Movimientos Sociales hacia el ALBA, 2012, «El ALBA de los Movimientos Sociales», en http://www.albamovimientos.org/wpcontent/uploads/2012/06/ALBARio.pdf [consulta: 10 de noviembre de 2012].

Brito García, Luis, 2009, América Nuestra: integración y revolución, t. II, Fondo Cultural del ALBA, Caracas.

Calderón, Fernando, 1995, Movimientos sociales y política: La década de los ochenta en Latinoamérica, Sigo XXI Editores, México.

Carrera, Jorge, 2005, El dilema Mercosur ¿Avanzar o retroceder?, Capital Intelectual, Buenos Aires.

Castells, Manuel, 1997, La era de la información, v. 2, Alianza editorial, Madrid.

Ceceña, Ana Esther, 2001, «Por la humanidad y contra el neoliberalismo, líneas centrales del discurso zapatista» en Resistencias mundiales: de Seattle a Porto Alegre, compilado por José Seoane y Emilio Taddei, CLACSO, Buenos Aires, pp. 131-140.

CMS-ALBA, 2009, «Manifiesto de la primera cumbre de movimientos sociales, pueblos y naciones de los países miembros de la Alianza Bolivariana para los Pueblos de Nuestra América», presentado en la Primera Cumbre de Consejo de Movimientos Sociales del ALBA-TCP, Cochabamba.

Díaz, Karla, 2011, «Diplomacia de los Pueblos: Participación popular en las relaciones internacionales», en Revista América Latina, n. 10, Arcis, Santiago de Chile, en http://www.academia.edu/1893900/Diplomacia_de_los_Pueblos_Participacion_Po pular_en_las_Relaciones_Internacionales [consulta: 15 de noviembre de 2012].

Dieterich, Heinz, 2007, «La integración regional y el socialismo del siglo xxi avanzan en América Latina» en: http://www.rebelion.org/noticia.php?id=47441 [consulta: 10 de diciembre de 2012].

Garcés, Mario, 2007, «Balance de los movimientos sociales en el Mercosur. Pistas para los procesos de integración regional» ponencia presentada en Seminario Movimientos Sociales en el Mercosur, 5 y 6 de noviembre, Santiago de Chile.

Garcés, Mario, 2012, El despertar de la sociedad, LOM, Santiago de Chile. 
García Linera, Álvaro, 2011, «Las tensiones creativas de la revolución: la quinta fase del proceso de cambio» en Serie Cuadernos, n. 7, FLACSO, Río de Janeiro.

Garretón, Manuel Antonio, 2004, América Latina en el siglo XXI: hacia una nueva matriz sociopolítica, LOM, Santiago de Chile.

Harnecker, Martha, 2002, Sin Tierra: Construyendo movimiento social, Siglo XXI de España Editores, Madrid.

Katz, Claudio, 2006, El rediseño de América Latina. ALCA, Mercosur y alba, Ediciones Luxemburg, Buenos Aires.

Martí i Puig, Salvador, 2010, «Los Movimientos Sociales» en http://campus.usal.es/ dpublico/areacp/materiales/Losmovimientossociales.pdf [consulta: 01 de junio de 2012].

Moulian, Tomas, 2001, Socialismo del siglo XXI: La quinta vía, LOM, Santiago de Chile.

Portela de Castro, María Silva, 2007, «El sindicalismo frente al Mercosur», Revista Nueva Sociedad, n. 211, Fundación Friedrich Ebert, Buenos Aires, en http://www.nuso. org/upload/articulos/3457_1.pdf [consulta: 01 de noviembre de 2012].

Programa Mercosur Social y Solidario, 2010, «La integración regional: balances y desafíos para los movimientos sociales» trabajo presentado en Panel de Debate Foro Social Américas (FSA), en http://mercosursocialsolidario.org/index.php?option=com_ content\&task=view\&id=518\&Itemid=54 [consulta: 15 de noviembre de 2012].

Rondón de Sansó, Hildegard, 2009, El régimen jurídico de los hidrocarburos: el impacto del petróleo en Venezuela, Epsilon, Caracas.

Seoane, José, Emilio Taddei, Clara Algranati, 2006, «Las nuevas configuraciones de los movimientos populares en América Latina» en Política y movimientos sociales en un mundo hegemónico. Lecciones desde África, Asia y América Latina, compilado por Atilio Borón y Gladys Lechini, CLACSO, Buenos Aires, pp. 227-250.

Serbin, Andrés, 2010, Regionalismo y soberanía nacional en América Latina: los nuevos desafíos, Nueva Sociedad, Buenos Aires. 
Sistema Unitario de Compensación Regional de Pagos (SUCRE), 2013, en http://www.sucrealba.org/index.php?q=content/el-sucre-presente-por-segundo\%C3\%B1o-en-la-feria-internacional-de-la-habana [consulta: 15 de noviembre de 2012]

Sousa Santos, Boaventura de, 2001, «Los nuevos movimientos sociales» en Osal, n. 5, CLACSO, Buenos Aires, pp. 177-188.

Svampa, Maristella, 2010, «Movimientos sociales, matrices socio-políticos y nuevos escenarios en América Latina» en Working Papers, n. 1, Universität Kassel, en http://kobra.bibliothek.unikassel.de/bitstream/urn:nbn:de:hebis:342010110334865/ 1/OWP_Working_Paper_2010_01.pdf [consulta: 25 de octubre de 2012].

Ticona, Esteban, 2006, La diplomacia de los pueblos, la diplomacia indígena: Hacia la descolonización de las relaciones internacionales, inédito, La Paz.

Vázquez, Mariana, 2008, «Los escenarios de participación social en el Mercosur» en Los nuevos enfoques de la integración: más allá del regionalismo, compilado por Grace Jaramillo, FLACSO, Quito, pp. 137-148.

Zibechi, Raúl, 2003, «Los movimientos sociales latinoamericanos: tendencias y desafíos» en Osal, n. 9, CLACSO, Buenos Aires, pp. 185-188.

Zibechi, Raúl, 2009, «La compleja relación entre gobiernos y movimientos ¿Autonomía o nuevas formas de dominación?», en http://www.rebelion.org/noticia.php?id= 79630 [consulta: 15 de noviembre de 2012].

\section{NOTAS}

\footnotetext{
${ }^{1}$ Venezuela se convirtió en el primer país miembro del bloque en aprobar a nivel legislativo el Protocolo de Adhesión del Estado Plurinacional del Bolivia al Mercosur. Según consta en Gaceta Oficial de la República Bolivariana de Venezuela n. 40.217 de fecha 30 de julio de 2013.

${ }^{2}$ El FCES es un organismo inspirado en el Comité Económico y Social (CES) de la Unión Europea, creado atendiendo a la demanda de mayor participación de los sectores empresariales y sindicales.

${ }^{3}$ Las Misiones Sociales son instrumentos del poder ejecutivo para la satisfacción inmediata y concreta de las necesidades colectivas (Rondón de Sansó 2009: 418), en materias tan diversas como alfabetización y
} 
educación a todos los niveles, salud, alimentación, formación para el trabajo, apoyo a las comunidades indígenas, entre otras.

${ }^{4}$ En aquel momento Hugo Chávez explicó: «se trata de retraer o de traer nuevamente un sueño que creemos posible, se trata de otro camino, se trata de una búsqueda, porque ciertamente la integración para nosotros es vital: o nos unimos o nos hundimos. Escojamos pues las alternativas» (ALBA-TCP 2013).

${ }^{5}$ Tratados de Libre comercio impulsados por EEUU bilateralmente con cada país.

${ }^{6}$ Movimientos presentes en conferencia de prensa en el Foro Social Temático, realizado en Porto Alegre, el 27 de enero de 2012, y Conferencia de Prensa del 2 de octubre de 2012 en Caracas, en manifestación de apoyo a la candidatura de Hugo Chávez en las elecciones del 7 de octubre.

${ }^{7}$ «La movilización social derribó dos presidentes en Ecuador y en Argentina, uno en Paraguay, Perú y Brasil, y desbarató los corruptos regímenes de Venezuela y Perú» (Zibechi 2003: 185).

${ }^{8}$ Tienen la característica común de intentar la transformación del Estado a partir de procesos constituyentes populares y nuevas constituciones.

Fecha de recepción: 23 de diciembre de 2012.

Fecha de aceptación: 12 de julio de 2013. 